\title{
Diáspora, interculturalidade e memória em En tierra extraña ${ }^{1}$
}

\author{
Rafael Tassi Teixeira \\ Denise Cogo
}

Resumo: O trabalho explora as relações entre os processos de mobilidade transnacional e a construção das subjetividades nas representações dos emigrantes no documentário En tierra extraña (BOLLAíN, 2014), tendo como metodologia principal uma análise sociocrítica do filme articulada à contextualização da cinematografia espanhola no campo das migrações. Os deslocamentos humanos lidos com base nas imagens fílmicas dos emigrados espanhóis contemporâneos são tensionados na cinematografia espanhola mais recente, sobretudo, na intensificação da percepção social do fenômeno da mobilidade emigrante a partir da crise econômica de 2008, e a experienciação da memória, diáspora e interculturalidade são observadas no filme de Bollaín em relação às narrativas temporais subjacentes aos recentes deslocamentos de espanhóis na Europa.

Palavras-chave: análise dos discursos cinematográficos; cinema e migração; identidades, estudos visuais e adaptabilidade.

Abstract: Diaspora, interculturality and memory in En tierra extraña (Iciar Bollain, 2014) The work explores the relationships between the processes of transnational mobility and the construction of subjectivities in migrant representations in the documentary En tierra extraña (Icíar Bollaín, 2014), whose main methodology is a sociocritical analysis of the film articulated to the contextualization of Spanish cinematography in the field of Migrations. The human displacements read from contemporary Spanish emigres' film images are stressed in the most recent Spanish cinematography, especially in the intensification of the social perception of the phenomenon of emigrant mobility from the economic crisis of 2008, as well as the memory experience, diaspora and interculturality are observed In Bollain's film in relation to the temporal narratives underlying the recent displacements of Spaniards in Europe.

Keywords: analysis of cinematographic discourses; Cinema and migration; Identities, visual studies and adaptability.

Versão revisada de artigo apresentado e publicado nos anais do IV Congreso Internacional Historia, Arte y Literatura en el Cine en Español y en Portugués - CIHALCEP2017, realizado na Universidad de Salamanca, Espanha, de 28 a 30 de junho de 2017. 


\section{Fluxos migratórios na realidade fílmica espanhola}

Esse texto tem como proposta abordar as relações entre os processos de mobilidade transnacional e a construção das subjetividades nas representações dos emigrantes no cinema espanhol, focalizando especificamente o documentário En tierra extraña (Icíar Bollaín, 2014), com base em uma análise sociocrítica do filme, articulada à contextualização da cinematografia espanhola no campo das migrações.

A cinematografia espanhola mais recente tem explorado com bastante representatividade aspectos da realidade migratória espanhola e como os deslocamentos humanos agem sobre a produção audiovisual em relação às subjetividades transnacionais. O filme-marco que reescreve a questão do choque cultural e a incomunicabilidade dos 1990 em relação às migrações ${ }^{2}$ é As cartas de Alou (Montxo Armendáriz, 1991). Filme significativo porque reverbera como as condições da insularidade nas relações humanas, dentro do choque de imaginários simbólico-sociais da Espanha do passado com a nova geopolítica da modernidade acaba rompendo o mito da impermeabilidade das fronteiras. As cartas de Alou é, também, importantíssimo porque se trata de um dos primeiros filmes que dedica toda a construção narrativa ao cenário migrante, centrando-se na imagem de Alou, um imigrante africano que descobre as várias dificuldades de imersão social na sociedade espanhola daquele momento. Em perspectiva similar, a partir dos 1990, vários outros filmes sobre os fluxos migratórios revelam-se fundamentais porque começam a lidar frontalmente com os problemas de incorporação de coletividades na realidade hispânica e tratam de modo significativo o fenômeno das migrações no audiovisual na Espanha: Said (Llorenç Soler, 1998), Flores de otro mundo (Icíar Bollaín, 1999), Extranjeras (Helena Taberna, 2003), 14 qilómetros (Gerardo Olivares, 2007), Querida Bamako (Omer Oké e Txarli llorente, 2007), Si nos dejan (Ana Torres, 2004), Cayuco (María Miró, 2009) etc.

Repletos de insistências sobre o drama contemporâneo dos migrantes, entrelaçam as características do cinema dos 2000 (incomunicabilidade, sensação acelerada do passo do tempo, infelicidade e culpabilização coletiva etc.) como revela Cousins (2013), com as alteridades negativizadas e o domínio, sem precedentes, dos fluxos transterritoriais. Nesse sentido, a partir desse período, enquanto bloco temático, os filmes são cada vez mais comprometidos em destacar os dramas individuais e as subjetividades impactadas com e a partir dos deslocamentos humanos. Revelam, dentro do paradigma da impressão de representação, uma tendência crítica em observar os problemas de convivência, as dificuldades e facilidades dos espaços interculturais, as políticas de seletividade social e o drama das fragmentações familiares impostos pelas restrições migratórias (SASSEN, 2013).

2 Os termos "migrante" e "migrações" são utilizados nesse texto para fazer referência aos fluxos que abrangem simultaneamente os movimentos de entrada de migrantes na Espanha e de saída de seus nacionais para outros países, do ponto de vista da cinematografia espanhola. Já o emprego dos termos "emigrante" e "emigração" visam enfatizar exclusivamente os movimentos de deslocamento de espanhóis para outros contextos nacionais, ao passo que o uso dos termos "imigrante" e "imigração" aludem especificamente à presença de nacionais de outros países na Espanha. 
Muito prevalentes no cinema dos 2000 (FRANÇA; LOPES, 2010; BERGFELDER, 2005), os movimentos migratórios no cinema assumem a condição de problematizarem os processos de fluxos transnacionais pela importância de fragilizar os estereótipos audiovisuais e, ao mesmo tempo, conseguir atingir a autonomia representativa sem direcionar exclusivamente ao migrante (ao minoritário, ao não incorporado etc.) as únicas possibilidades narrativas. Ou seja, a partir do encontro e do enfrentamento com a alteridade arbitrada, emergem filmes, na realidade espanhola, como Cosas que dejé en La Habana (Manuel Gutiérrez Aragon, 1997), Taxi (Carlos Saura, 1996), En la puta calle (Enrique Gabriel, 1997), El traje (Alberto Rodríguez, 2002), Salvajes (Carlos Molinero, 2001), Ilegal (Ignacio Villar, 2002) que significativamente produzem uma espécie de conjugação entre a linguagem visual - muito próxima à estilística do documentário (ESCUDERO, 2014) -, e a crítica social contundente, apontada em filmes como O ódio (Mathieu Kassovitz, 1995) e Biutiful (Alejandro González Iñárritu, 2010).

Nesse sentido, as invisibilidades clássicas dos migrantes no cinema mundial, destacadamente a partir do cinema dos anos 1990 e, com maior força temática-estilística em vários filmes dos 2000, começam a ser substituídas por contextos fílmicos que pautam as questões transnacionais mais recentes: novas etnicidades sustentadas por globalizações precárias, recorrentes em filmes como L'Esquive (Abdellatif Kechiche, 2005); trânsitos humanos como resistências, como em La jaula de oro (Diego Quemada-Díez, 2013); relações interétnicas, como em Françoise (Souad El Bouhati, 2007). As características de um cinema diaspórico e transnacional (TASSI, 2016) passam, dessa forma, a dar maior atenção à alteridade em paisagens mais caleidoscópicas, ao mesmo tempo fragmentárias e microcósmicas - reveladoras das distâncias que apenas aumentam, apesar dos afetos, apesar dos corpos.

Representativamente na Espanha (MONTERDE, 2008), o cinema começa com mais intensidade a pensar as relações humanas transnacionais em um sentido que ao mesmo tempo explora e sistematiza a distâncias entre as políticas migratórias e as variadas situações de convivência. As dicotomias frágeis ("autóctones" e "estrangeiros") parecem, portanto, cada vez mais deslocadas em uma multiplicidade de filmes que se destacam pela força com que negam as narrativas únicas - obstinadamente confirmadas pelos agentes políticos e pelos meios de comunicação. Cinematograficamente há um avanço determinante, nesse aspecto, na preocupação em formar multiplicidades de imagens que revelem narrativas mais condizentes com as realidades retratadas, ao mesmo tempo sem perder a profundidade psicológica dos personagens e sem esquecer dos jogos de sentido e realidade sempre imbricados nas representações fílmicas ${ }^{3}$.

3 Como aponta Santaolalla (2005), o papel dos imigrantes será fundamental nessa perspectiva, dentro do cinema espanhol, porque se trata, cada vez menos, de evitar o tratamento sinedóquico das formas representativas das alteridades e sim entendê-las como estruturantes em imaginários comuns de imposição que, ao conceder voz ativa aos protagonistas fílmicos, emergem potencialidades reflexivas, subjetividades mais ou menos conscientes e apreensivas em relação às suas identidades de origens, aos seus laços passados e construídos, às suas trajetórias e às biografias diaspóricas. 
Em relação ao cinema espanhol (CASTIELLO, 2005), as novas cartografias transnacionais incidem sobre a problemática das migrações humanas por meio das dificuldades de materialização dos contextos de incorporação. É na formação de mentalidades mais complexificadas que se relativizam, dentro de cinematografias mais comprometidas com a realidade, as identidades e como estas são densificadas diante dos processos de deslocamentos (lidos como polissêmicos e repletos de decisões significativas nas biografias expostas). A dimensão cinematográfica espanhola, nesse sentido, consegue pensar os processos de trânsito como imbricados na organização de uma imagem que se destaca, da mesma maneira que o cinema 'transcultural' dos 1990 começava anteriormente a promover (NEWMAN, 2010), na sedimentação da ambiguidade das relações humanas e na obrigatoriedade de ruptura com os imaginários midiáticos sobre os deslocamentos humanos.

Filmes como En construcción (José Luis Guerín, 2000), Ilegal (Ignacio Villar, 2002) ou Princesas (Fernando León de Aranoa, 2005) conseguem problematizar de uma forma mais contundente as representações sobre os migrantes porque se apoiam tanto em desprogramar as ausências das representações das minorias no cinema na demarcação das subjetividades subalternizadas (SHOAT; STAM, 1994), como em avançar sobre as variadas dimensões do cotidiano e a importância das aproximações interculturais nas imagens da alteridade migratória ${ }^{4}$. A importância de filmes como En la puta calle (Enrique Gabriel, 1997), Cosas que dejé en La Habana (Manuel Gutiérrez Aragon, 1997) ou Flores de otro mundo (Icíar Bollaín, 1999) está em guardar uma profunda relação com a necessidade de avançar sobre a desconstrução dos antigos estereótipos e, ao mesmo tempo, aproximar-se da temática dos marginalizados, excluídos, negados pelos discursos hegemônicos ${ }^{5}$.

Em relação ao documentário, além de En construcción, filmes fundamentais como Extranjeras (Helena Taberna, 2003), 14 kilómetros (Gerardo Olivares, 2007), Querida Bamako (Omer Oké e Txarli Ilorente, 2007), Si nos dejan (Ana Torres, 2004), Cayuco (María Miró, 2009), Destino clandestino (Dominique Mollard, 2008) e Apuntes para una odisea soriana interpretada por negros (LLorenç Soler, 2005), articulam a problemática das diferenças em contextos diversos e 'pensam' cinema ao mesmo tempo em que pensam as questões migratórias: o cinema, nesse processo, passa a interferir nas relações interétnicas não apenas como observador distanciado e como crítico contundente das mesmas; passa a realizar uma profunda discussão sobre os paradigmas normativos das admissões, sobre as dificuldades das micro escolhas migratórias, sobre a consequência das expectativas

4 En construcción (José Luís Guerín, 2000) é um filme significativo nesse movimento porque repete a condição do migrante com uma alternativa sensível e ao mesmo tempo situacional das relações humanas dentro de paisagens em constante transformação - o bairro barcelonês de Raval, crisol de múltiplas subjetividades provenientes de várias realidades migratórias. De certa forma, o filme também reverbera a própria condição da memória e os lugares do pertencimento histórico ao pensar as transformações urbanísticas da Espanha 'econômica' dos 2000, filtrando para dentro do jogo cinematográfico os relatos dos trabalhadores da construção civil e dos imigrantes, certamente em uma metáfora da convivência possível e realizável (dividindo o plano fílmico nas falas do migrante marroquino e seu companheiro espanhol).

5 Com uma forte inspiração em cineastas comprometidos com a qualidade estilística e a discussão da realidade social, espelho do cinema de Ken Loach, por exemplo. 
não cumpridas e o desejo de reescrever o próprio destino. Para dentro do filme - o filme documentário, onde ele se compromete em perder direito de não criar e repercutir na realidade - as questões migrantes alimentam a própria natureza dos processos fílmicos. O documentário migratório espanhol tem algo de (ins)urgente, como escreve Ballesteros $(2001)^{6}$, que desestabiliza as noções referenciais da alteridade migrante apontando para um denominador comum: a intolerância não vence os afetos, mas a xenofobia segue determinada e resistente (em que pese as representações positivas do próprio).

Nesse sentido, tanto Extranjeras (Helena Taberna, 2003) como, por exemplo, Apuntes para una odisea soriana interpretada por negros (LLorenç Soler, 2005) são filmes que problematizam as questões migratórias por meio do documentário abrindo espaço para a polifonia de vozes articuladas pelas discursividades femininas e também extraem do documentário a temática da possibilidade das mulheres migrantes serem lidas como sujeitos de seu próprio destino. Exploram, pelo domínio da experiência individual, a condição de sujeitos que realizam, especialmente por meio do empoderamento discursivo e da vocação - aberta - da necessidade de estabelecer um cuidado com as biografias, suas novas experiências individuais. As narrativas migrantes, nesses exemplos, são, no fundo, contranarrativas que espelham processos de deslocamentos transnacionais onde as histórias de vida desconstroem muitas das falsas premissas sobre os imigrantes na Espanha. Dentre elas, destacam-se aquelas premissas que reiteram que os imigrantes formam um grupo homogêneo, que estão inseridos em determinados 'nichos' de trabalhos, que não existem preferências na hora de contratar, e que o desejo que impera é, sobretudo, de que não formem laços familiares ou tragam os parentes para o contexto espanhol.

Nesse aspecto, os documentários que tratam de temáticas migrantes acabam por trazer a tarefa dupla de identificar a pluralidade de vozes e apresentar um regime de sensibilização das migrações transnacionais. Provavelmente desde o significativo filme de Guerín (En construcción), em ressonância crescente com o cinema mundial (DENNISON, 2013), os documentários sobre os deslocamentos migratórios na Espanha sejam caracterizados pelo tratamento intercultural que rompe com a série de imprecisões e redundâncias normalmente vistas nos meios de comunicação do país (NASH, 2005). Uma força cinematográfica que passa a intensificar os fluxos migratórios e a condição do desterro, da errância, da incorporação difícil - e 'difícil', muitas vezes, como observamos em En construcción, mais para os programadores das agendas políticas que para os próprios 'autóctones' nas suas confrontações cotidianas com os 'estrangeiros' -, sempre com base nas ligações entre as histórias sensíveis e o trânsito entre identidades e desenraizamentos.

Parte dessa concepção destacadamente não utilitarista está no modo com que a $\mathrm{s}$ imagens passam a ser metamorfoses do social sobre a crítica às próprias insistências midiáticas e cinematográficas. O documentário espanhol (CATALÀ, 2012), nesse sentido,

6 Na perspectiva, segundo o autor, de ser contestador das narrativas fílmicas, mas também o caleidoscópico dos universos os quais dimensiona e também perfura. 
desconfigura a realidade porque aprofunda os espaços em que a ideia de real é concebida como uma maneira de definir regimes de representação aparentemente sem fissuras ou sem reconhecimento da parcialidade das 'modalidades de ficção' (RANCIÈRE, 2010) dentro de uma noção de relativismo dos mecanismos observadores-observados.

Os documentários de natureza migratória, nesse sentido, seguem um alinhamento percebido nos principais debates da teoria do documentário antes dos anos 1990. Nesse aspecto, a ensaística migratória nos documentários posteriores à década de 1990 (ESCUDERO, 2014) entende o rol dos sujeitos em transição dentro da primeira ação intensamente significativa: a capacidade de ressonância do efeito da partida que o sujeito migratório tem dentro da liminaridade da experiência migrante. Conforme reflete Tassi (2016), o cinema migratório enuncia os processos de transposição de localidades por meio da visão da heterogeneidade e da polissemia do fenômeno, carregado de consonâncias narrativas que precisam ser decupados em uma lógica chave da política da identidade na ação da partida. As migrações humanas, como processos complexos e carregados de labilidade discursiva, são exploradas no cinema transcultural diaspórico (NACIFY, 2001) por meio de suas lógicas impeditivas e de seus rastros de significação: a maior parte do cinema ficcional anterior à década de 1990 (FRANÇA; LOPES, 2010) joga a responsabilidade moral, jurídica e cultural ao imigrante, esquecendo de pensar as ausências e a desconstrução da subjetividade do modelo representacional. Os documentários migratórios, por sua vez, desenham-se orquestrados possivelmente na posição paralela instituída pela antropologia (D'ANDRADE, 1995; CLIFFORD, 1995; BARNAND, 2000) e pela antropologia visual (PINK, 2000; EL GUINDI, 2004), em que as imagens culturais e o processo de historicização bastante crítico com a posição dos enunciados - enunciadores, são ponto de partida da própria história da disciplina.

O cinema, no caso espanhol, desenvolve a característica fundamental de ser um lugar de ressonância dos processos interculturais e subjetivos nos deslocamentos humanos. A contraofensiva importante feita pelo documentário na Espanha, pelo menos desde a segunda metade dos 1990, se assenta na crítica frontal aos discursos xenofóbicos que os imaginários sucessivos sobre a realidade social migratória são disseminados nos meios de comunicação. A cinematografia sobre os processos transnacionais na Espanha aumenta com a percepção social do fenômeno, tal como apresenta Santaolalla (2005), mas é o filme documentário e as suas profundas reflexões sobre aquilo o que disseca e o que está em risco - entre os jogos de ficção e realidade - que sucessivamente marca pontos de inflexão fundamentais (En construcción, José Luis Guerín, 2000; Extranjeras, Helena Taberna, 2003; Apuntes para una odisea soriana interpretada por negros, Llorenç Soler, 2005; etc.) na história recente da percepção da alteridade migrante e na tentativa de desconstrução dos binarismos midiáticos. 


\section{En tierra extraña (Icíar Bollaín, 2014)}

As imagens dos espanhóis emigrados repercutem na construção fílmica do documentário espanhol En tierra extraña. Dirigida por Icíar Bollaín, retrata a situação de vários espanhóis que, a partir da crise econômica de 2008, foram obrigados a deixar a Espanha ${ }^{7}$ em busca de melhores condições de trabalho ${ }^{8}$.

Centrando-se na frustração pela impossibilidade em conseguir, dentro do país de origem, desenvolver minimamente um lugar laboral possível para aquilo que foram (em geral, altamente) qualificados, o documentário explora os discursos e narrativas dos jovens emigrantes espanhóis na capital escocesa, Edimburgo. O filme desenvolve reflexivamente os sentimentos de indignação e ao mesmo tempo nostalgia da saída forçada da Espanha; acompanha as decepções dos emigrantes relacionadas ao país que, da mesma forma que muitos de seus antepassados, precisam sair para poder sobreviver. O tratamento diegético explora as historicidades da questão migratória nas narrativas dos emigrados, desenvolvendo um movimento de intersecção entre as vozes dos emigrantes na cidade de Edimburgo em paralelo com pelo menos três níveis de situação fílmica: (a) percepções dos emigrantes; (b) obra de teatro (monólogo da peça Autorretrato de un joven capitalista español, de Alberto San Juan); (c) acompanhamento de uma cena artística por uma das protagonistas do filme (sessão fotográfica com as luvas coletadas por Gloria, estudante de Belas Artes na Espanha).

O documentário de Icíar Bollaín abre com a imagem de um guante, metáfora visual solitária do processo de perda, incompletude e impossibilidade que atinge milhares de emigrantes espanhóis apenas em Edimburgo (20.000, segundo o filme). Com o andamento fílmico, descobrimos que faz parte de um projeto desenvolvido por Gloria, uma andaluza formada em Belas Artes na Espanha e professora aprovada três vezes em concursos públicos - ainda assim, sem ser chamada para ocupar a vaga. Em três níveis diegéticos (obra de teatro do ator Alberto San Juan, cena artística projetada por Gloria, vozes dos emigrantes) utiliza-se de algumas imagens de arquivo, de vídeos em preto e branco sobre emigrantes espanhóis das décadas de 1950-70 e narrativas de pesquisadores (comentário

7 Dados do INE (Instituto Nacional de Estadística) evidenciam um decréscimo da população espanhola em 26.501 habitantes durante a primeira metade de 2015, confirmando a redução populacional registrada pelo país nos últimos três anos. Ver http://www.ine.es/prensa/np948.pdf. Em 1o de julho de 2015, a Espanha contava com um total de 46.423.064 habitantes, situando-se, ainda, entre os países da União Europeia que registraram um saldo migratório negativo, resultante do retorno de migrantes a seus países de origem, assim como do incremento da emigração de cidadãos espanhóis a partir da crise de 2008. Em 30 de junho de 2016, o mesmo INE divulgou dados que registram a saída do país de 98.934 espanhóis durante o ano de 2015, a cifra mais alta registrada desde o início da crise de 2008 e que representa um aumento de $23 \%$ em relação ao ano de 2014. Disponível em: < http://politica.elpais.com/politica/2016/06/30/actualidad/1467280825_063213.html>. Acesso em: dez 2016 (TASSI, OLIVERA, 2017).

8 A emigração espanhola dos últimos oito anos está constituída principalmente por jovens que foram afetados pela redução da oferta de trabalho. A "Encuesta de Población Activa (EPA)" realizada pelo INE aponta que, em meados de 2014, o maior número de desempregados no país concentrava-se na faixa etária de 25 a 34 anos, totalizando 176.700. A taxa de desemprego juvenil registrou uma alta de $55 \%$ nos primeiros meses de 2014 pelo segundo trimestre consecutivo. Disponível em: <http://www.ine.es/dyngs/ INE base/es/operacion.htm?c=Estadistica_C\&ci $\mathrm{d}=1254736176918 \&$ menu=ultiDatos\&idp=1254735976595>. Acesso em: dez 2016. (TASSI, OLIVERA, 2017). 
de sociólogo-teólogo), para explicar o fenômeno recente dos novos deslocamentos migratórios espanhóis na Europa.

O tratamento diegético potencializa as narrativas emigrantes com a centralidade dos discursos. Há um mecanismo de intersecção das falas dos jovens espanhóis com a obra de teatro do ator Alberto San Juan, e o filme estrutura-se em um movimento importante: a decepção e a nostalgia do processo de deslocamento migratório incide na construção de falas que vertebram reflexões compartilhadas sobre o processo de distanciamento. A experiência emigratória é observada com uma proposta intercultural que relativiza o próprio filme por meio de um jogo de mensagens sobre o passado insistente como migrante e sua reprodução parcial - mas mais funda a decepção, alimentada pelo contexto histórico persistente ${ }^{9}$.

Em três níveis fílmicos, portanto, En tierra extraña avança destacando o marco atual do contexto emigratório espanhol (mas também de muitos jovens europeus) e a insistência com que o fluxo de imigrantes/emigrantes incide sobre sociedades reféns de sistemas políticos que parecem insistir sobre o capital humano como se de interesses e excedentes se tratasse. O filme de Bollaín aponta várias vezes sobre essa dimensão agressiva da alteridade dicotomizada pelos meios de comunicação e a canibalização dos mais jovens, daqueles que sofrem com as mudanças repentinas do sistema político com a naturalização do lema: 'não há espaço para todos'. A culpabilização do jovem emigrante, principalmente por certo esquema político que esquematicamente designa 'emigrados' como 'aventureiros', é bastante enfatizada na mise-en-scène como proposta crítica ao distanciamento das vozes governamentais das realidades sociais dos emigrantes. O filme, desse modo, aprofunda a dimensão crítica das representações hegemônicas disseminadas irresponsavelmente pelos agentes do estado espanhol ao mostrar, na composição de narrativas dos emigrantes na Edimburgo europeia, a distância entre os discursos oficiais e o drama dos emigrantes ${ }^{10}$.

Não há, também, descuido na questão intercultural: En tierra extraña acompanha as falas dos jovens espanhóis e intervala aspectos do cotidiano migratório (as dificuldades da integração sem tempo e equânimes condições de estar preparado, o custo individual e psicológico do empreendedorismo, a nostalgia com o país deixado forçosamente etc.) com a dimensão macro dos deslocamentos (a reprodução dos sistemas políticos em notadamente falharem na promessa da integração de todos). Ao correlacionar os dramas dos jovens emigrantes na Edimburgo de 2014 com as imagens do passado, o filme mostra como os sistemas políticos por um lado mentem ao imprimir uma imagem (europeísta)

9 Em dado momento do fluxo fílmico, vemos a fala do avô de Glória, emigrante espanhol na década de 1960, que relata um comentário de um amigo que lhe impactou: "Maldita pátria que no da de comer a sus hijos... eso me dijo un español, a lagrima suelta, en Alemania, y nunca se me olvida"

10 Comentários de políticos do governo, a respeito da 'integração europeia' nos fluxos de saída e do 'impacto na experiência vivencial' dos jovens espanhóis emigrados, cuidadosamente inseridos em momentos específicos do documentário, destacam a incapacidade dos governantes em compreenderem o nível de indignação dos que foram obrigados a sair do país de origem, por exemplo na fala de Mariví, uma comerciante desempregada que se vê obrigada a emigrar a Edimburgo: "Me han obligado, me han sacado a patadas... yo no merecía esto." 
de avanço social e, por outro, fracassam sistematicamente em conseguir promover a inserção social daqueles que, vemos no fluxo fílmico, acabam sendo os netos e bisnetos dos que emigraram anteriormente. Nesse sentido, o filme apresenta com uma significativa intencionalidade crítica a reprodução dos movimentos históricos ao mesmo tempo em que apresenta as narrativas emigrantes com a proposta da cena artística "ni perdidos ni calados", que Gloria, expulsa do sistema social espanhol, desenvolve na Edimburgo contemporânea ${ }^{11}$.

O documentário de Bollaín, ainda, densifica as narrativas emigrantes coincidindo-as com o tempo da imagem cinematográfica: o uso de imagens de arquivo e a importante duplicação das vozes dos narradores com as coincidências e as especificidades dos emigrados, marcam uma correlação que provavelmente acaba por mostrar a insistência com que as indignações ressoam pelo presente 'europeísta' e pelo passado isolado. Observamos que a integração está relacionada ao empreendedorismo migratório e às variadas situações individuais, mas, sobretudo, como o passado emigrante segue vertendo-se sobre um futuro que se torna geográfica e comunicacionalmente mais próximo, mas segue sendo impeditivo e fronteiriço: os sucessivos limites linguísticos, nacionais, sociais e hierárquicos na admissão e integração de pessoas.

Bollaín inscreve a ação documentarista em uma estratégia inteligente de atar as falas dos espanhóis aos aspectos coletivos da dimensão dos deslocamentos. Mostra como o protagonista oculto e sobrevivente - o sistema político que oculta crises para seguir existindo, a base de sonhos falsos e desterritorializações parciais - atinge uma nova geração de emigrantes e, em que pese às distâncias históricas, dissecam os mais de 5,4 milhões de desempregados que se movem porque precisam encontrar oportunidades e a subsistência que o sistema social não permite. A relação entre a memória migratória e a diáspora espanhola parece ser constituída pelo sistemático esquecimento dos fracassos sociais do passado e da reprodução dos mecanismos (a saída emigrante) como um meio de paliar as distâncias entre os projetos políticos e a incorporação das pessoas.

A centralidade dessa discussão parece se fortalecer na mise-em-scène porque Bollaín estabelece um processo de atenção em relação à emergência da questão da memória documentarista, uma vez que En tierra extraña ressoa a historicidade da construção enunciativa dos deslocamentos do passado e sua (obscena) insistência no presente ${ }^{12}$. O filme evoca, assim, por meio dos relatos dos "novos" e jovens emigrantes, a permanência de um certo imaginário coletivo, no contexto da sociedade espanhola, fundado na percepção de que o processo de modernização, industrialização e urbanização da Espanha,

11 A formação de um ativismo social significativo, que aproxima os emigrantes com a cena artística e o lema "ni perdidos ni callados", é também ampliado no documentário ao trabalhar com uma música extradiegética que exalta a formação de uma espécie de rede migratória e de um discurso comum: o teor de indignação dos que precisaram sair é ampliado pela percepção de que, mesmo sendo academicamente mais preparados que seus antepassados, ainda assim não encontram lugar dentro do sistema político (baseado na exclusão de pessoas).

12 En tierra extraña, de certo modo, dualiza com filmes sobre a emigração espanhola na Europa das décadas de 1950, 1960 e 1970, como Vente a Alemania, Pepe (Pedro Lazaga, 1971), Españolas en Paris (Roberto Bodegas, 1971), Un Franco, 14 Pesetas (Carlos Iglesias, 2006). 
sua entrada na União Europeia e sua inserção na ordem do capitalismo global e financeiro teria liberado definitivamente o país de sua condição histórica de país de emigração para posicioná-lo como país de imigração ${ }^{13}$. No entanto, o retorno a essa condição de um país que "expulsa seus nacionais" implicaria também na desestabilização do imaginário de um "país capitalista, moderno, desenvolvido e europeu" e ao mesmo tempo no reconhecimento da atual crise econômica e política provocada por esse mesmo capitalismo.

Além disso, o difícil enfrentamento dos jovens migrantes com a memória da emigração espanhola do passado (constituída majoritariamente por emigrantes "não qualificados") colabora igualmente para tensionar esse posicionamento da Espanha como país de emigração. Em seus relatos, os jovens parecem evidenciar uma certa perplexidade diante da realidade de "terem sido empurrados à emigração", e a "emigração ter sido uma experiência imposta", quando dispunham da formação educativa e da qualificação profissional necessárias (nível de escolarização superior, domínio de idiomas, vivências cosmopolitas por meio de mobilidades estudantis etc.) para encontrarem trabalho e assegurarem a sobrevivência em seu país de origem.

O documentário dá lugar, assim, à tessitura de uma memória em torno dos novos fluxos contemporâneos de emigração espanhola, impulsionadas pela crise de 2008, na qual as experiências diaspóricas dos jovens emigrantes parecem inicialmente demarcadas pela vivência da mobilidade como imposição e alternativa de sobrevivência (busca de trabalho) ${ }^{14}$ para, no decorrer do percurso migratório, ser experimentada também como espaço de vida e possibilidades de vivências cosmopolitas e interculturais. O que, em certo sentido, sugere possibilidades de articular memórias do passado e do presente sobre os deslocamentos de espanhóis. Nessa perspectiva, a precariedade enfrentada no mundo do trabalho ou a condição de "imigrantes do sul da Europa" que Ihes é atribuída, parece colaborar para fazer emergir, entre os jovens espanhóis, uma memória em torno de condição similar vivenciadas, na Espanha, pelos imigrantes de outras nações, especialmente quando, no final dos anos 90 e início dos anos 2000, o país recebeu um número expressivo de estrangeiros, posicionando-se, no cenário internacional, como uma das principais nações receptoras de imigrantes.

\section{Considerações finais}

As cartografias fílmicas mundiais têm conseguido, dentro de uma variedade bastante ampla de filmes que carregam como núcleo articulador perspectivas transnacionais e

13 Sobre Espanha como país de emigração e imigração, ver, dentre outros, Dahiri; Nieto-Morales; VázquezFernández (2016); Valero Matas et al. (2015) e Alted Vigil (2008).

14 Cabe lembrar aqui que a reiteração das narrativas dos jovens, de sua condição de emigrantes forçados remete a um tipo de posicionamento discursivo do governo e da mídia espanhola que tem construído a atual emigração de jovens como "aventura"; "ampliação de experiência profissional" ou "aprendizagem de idiomas". Discursos que têm sido confrontados, em termos contradiscursivos, em ativismos e mobilizações transnacionais de coletivos de jovens emigrantes espanhóis como Marea Granate (www.mareagrante.org) (COGO; OLIVERA, 2017). 
subjetividades em trânsito (FOSTER, 1999), produzir um tratamento temático mais exigente - e estilisticamente mais potente - das questões migratórias contemporâneas.

Não obstante, os problemas, silêncios, vulnerabilidades, situações de abuso de toda ordem e as múltiplas formas de insuficiências correlacionadas aos deslocamentos humanos, seguem intensificando o paradigma da mobilidade como uma das mais importantes forças de discussão das políticas de representação dentro dos imaginários audiovisuais recentes. O cinema espanhol não é, por tudo isso, de nenhuma maneira refratário à emergência da temática migratória em contextos de recepção e partida. Está inevitavelmente predisposto a ser aberto e em demarcar estruturalmente as várias mediações possíveis entre a memória migrante e a própria memória fílmica (VAN LIEW, 2008). Seu passado fílmico condensa, desde a ficção e o documentário, perspectivas cinematográficas fundamentais que ajudaram tanto a edificar como a descontruir o mito do emigrante/imigrante, seus 'lugares' de designação, seu empreendedorismo incansável, sua importância muito além dos fatores econômicos - e, mesmo mediocremente dentro dessa única visão, ainda assim tantas vezes negada sua contribuição estrutural.

O filme de Icíar Bollaín é um documentário valente que busca uma leitura polissêmica e aberta dos emigrados espanhóis na Edimburgo atual pela via da força do relato e da resistência da imagem. A proposta temática-estilística do documentário da diretora, dentro de três linhas - três profundidades narrativas -, densifica as falas dos jovens emigrantes espanhóis como uma forma de pensar as migrações e ao mesmo tempo incluir nela o que é mais indignante: repetir a tragédia, repercutir a história ouvindo que ela não esconde seus desenganos, seus ciclos resistentes, sua atualidade obstinada.

A força individual e ao mesmo tempo emergente dos relatos dos jovens espanhóis compõe um quadro de mediação frontal da memória emigrante (os ancestrais emigrantes na Europa) e os corpos dos novos deslocados, criando uma interposição significativa com as continuidades do passado (a eterna fragilidade que acompanha os migrantes) e os vários impedimentos que os demarcam. O que muda com a sensação que, apesar do empreendedorismo, apesar da qualificação sem precedentes dos emigrados espanhóis, o êxodo está inevitavelmente tapando uma mentira globalizatória: o acesso a todos, de forma plural, disponível e igualitária?

Essas três mediações fazem de En tierra extraña um filme fundamental para ajudar a pensar as sentidas formas com que a proliferação de processos de circulação de pessoas, na Europa atual, mesmo aos mais qualificados, aos mais jovens e europeus, seguem sendo metáforas da desigualdade e das relações de dominação. Como deriva da falsa cratera entre ficção e documentário, o filme traz à luz um vestígio contemporâneo concreto: o modo pelo qual a presença (da diáspora) impõe à exigência (da narrativa) para poder pensar, de forma atomística, o verdadeiro valor do âmbito da ação humana, da necessidade de falar e de ser ouvido, do imperativo da história e a sua reprodução tantas vezes infame e silenciosa. 
Rafael Tassi Teixeira é professor e vice-coordenador do Programa de Pós-graduação em Comunicação e Linguagens da UTP/PR e professor adjunto da Unespar\FAP (Sociologia da Arte e Estudos Culturais).

rafatassiteixeira@hotmail.com

Denise Cogo é professora titular do Programa de Pós-Graduação em Comunicação e Práticas de Consumo da Escola Superior de Propaganda e Marketing (ESPM) e pesquisadora 1D do CNPq.

denisecogo2@gmail.com

\section{Referências}

ALTED VIGIL, A. España, de país de emigrantes a país de inmigrantes. Universidad de Mayores de Experiencia Recíproca/Ministerio de Trabajo y Asuntos Sociales: Madrid, 2008. Disponível em: <http:// umer.es/wp-content/uploads/2015/05/n48.pdf> Acesso em: 21 maio 2017.

BALLESTEROS, I. Cine (ins)urgente: textos fílmicos y contextos culturales de la España posfranquista. Madrid: Editorial Fundamentos, 2001.

BARNAND, A. Theory and history in Anthropology. Cambridge: Cambridge University Press, 2000.

BERGFELDER, T. National, transnational or supranational cinema: rethinking european film studies. Media, Culture \& Society. v. 27, n. 3, p. 315-331, 2005.

CASTIELLO, C. Los parias de la tierra: inmigrantes en el cine español. Madrid: Talasa, 2005.

CATALÀ, J. M. D. El murmullo de las imágenes: imaginación, documental y silencio. Santander: Shangrila, 2012.

CLIFFORD, J. Dilemas da cultura: antropología, literatura y arte en la perspectiva posmoderna. Barcelona: Gedisa, 1995

COGO, D.; OLIVERA, M. N. \#NoNosVamosNosEchan - internet, activismo en red y narrativas de los nuevos emigrantes españoles. Matrizes (Online). v. 11, n.11, p. 165-187, jan-abr.2017. Disponível em: <http://www.revistas.usp. br/ matrizes/article/view/122220> Acesso em: 22 ago. 2017.

COUSINS, M. História do cinema. São Paulo: Martins Fontes, 2013.

DAHIRI, M.; NIETO-MORALES, C.; VÁZQUEZ-FERNÁDEZ, M. J. España de país de emigración a país de inmigración. Testimonios y relatos de vida de personas inmigrantes que residen en España. Una mirada desde la perspectiva de los sentimientos vividos. Madrid: Editorial Dykinson S.L., 2016.

D'ANDRADE, R. The development of Cognitive Anthropology. Cambridge: Cambridge University Press, 1995.

DENNISON, S. (Org.). World cinema: as novas cartografias do cinema mundial. Campinas, SP: Papirus, 2013.

EL GUINDI, F. Visual Anthropology: essential method and theory. Altamira Press, 2004. 
EN TIERRA Extraña. Direção: Icíar Bollaín. Madrid: Tormenta Filmes, 2014. 1 DVD (72 min)

ESCUDERO, P. M. Cine documental e innmigración en España: una lectura sociocrítica. Madrid: Comunicación Social ediciones y publicaciones, 2014.

FOSTER, G. Captives bodies: postcolonial subjectivity in cinema. Albany: State University of New York Press, 1999.

FRANÇA, A.; LOPES, D. (Orgs.). Cinema, globalização e interculturalidade. Chapecó: Argos, 2010. MONTERDE, J. E. El sueño de Europa: cine y migraciones desde el sur. Andalucía: Junta de Andalucía, 2008.

NACIFY, H. An accented cinema: exilic and diasporing filmmaking. Princeton University Press, 2001.

$\mathrm{NASH}, \mathrm{M}$. Inmigrantes en nuestro espejo: inmigración y discurso periodístico en la prensa española. Barcelona: Icaria Antrazyt, 2005.

NEWMAN, K. Notes on transnational film theory: decentered subjectivity, decentered capitalism, In: DUROVICOVÁ, N.; NEWMAN, K. World cinemas, transnational perspectives. NY: Routledge, 2010.

PINK, S. The future of Visual Anthropology. Taylor and Francis, 2000.

RANCIÈRE, J. A ficção documental: Marker e a ficção da memória. Revista Arte e Ensaios PPGAV \ EBA\UFRJ. n. 21, dez. 2010.

SANTAOLALLA, I. Los otros: etnicidad y «raza» en el cine español contemporáneo. Zaragoza: Prensa Universitaria, 2005.

SASSEN, S. Decipheringteh global: Its scales, spaces and subjects. Taylor \& Francis, 2013.

SHOAT, E.; STAM, R. Multiculturalismo, cine y medios de comunicación. Madrid: Paidós, 1994.

TASSI, R. Cine Diaspórico Iberoamericano: Fronteras, Itinerarios y Transculturalismos. Barcelona: UOC, 2016.

VALERO MATAS, J. A.; MEDIAVILLA, J. J.;VALERO OTEO, I.; COCA, J. R. El pasado vuelve a marcar el presente: la emigración española. Papeles de población. v. 21, n. 83, p. 41-74, 2015. Disponível em: <http://www.scielo.org.mx/scielo.php?script=sci_arttext\&pid=S140574252015000100003\&ln g=es\&tlng=es $>$ Acesso em: 21 maio 2017.

VAN LIEW, M. Inmigration films: conventions of (in)visibility in contemporary Spain. In: BECK, J.; RODRÍGUEZ, V. Contemporary spanish cinema and genre. Manchester: Manchester University Press, 2008.

Artigo recebido em maio e aprovado em julho de 2017. 